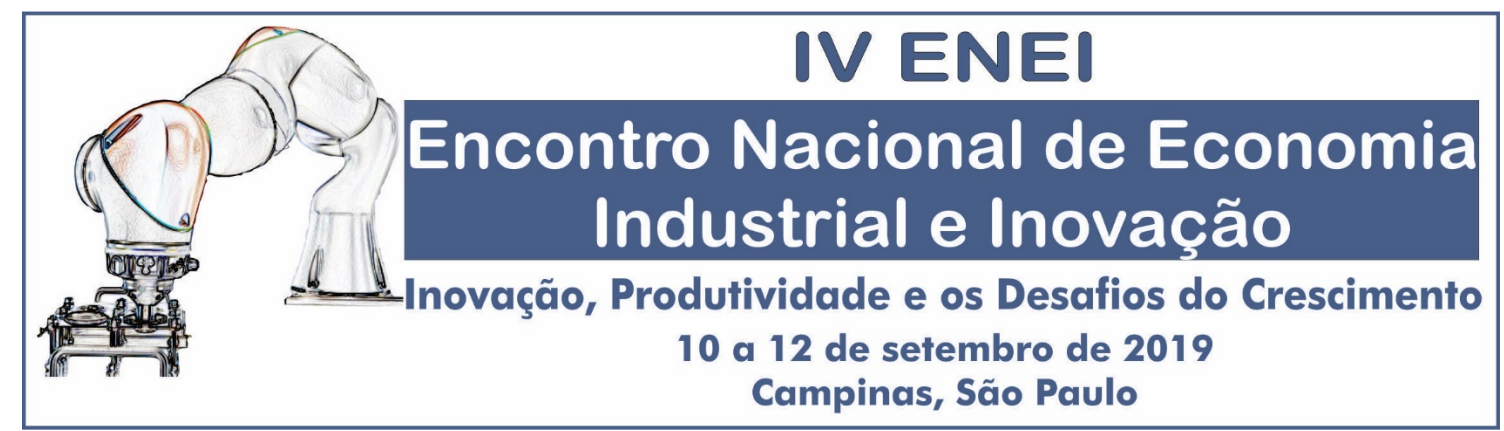

\title{
OS DESAFIOS DA INDÚSTRIA FARMACÊUTICA NO BRASIL
}

\author{
Hamilton de Moura Ferreira Júnior ${ }^{1}$ \\ Inara Rosa de Amorim ${ }^{2}$ \\ Ivanessa Thaiane do Nascimento Cavalcanti ${ }^{3}$ \\ Joana Azevêdo Fraga ${ }^{4}$
}

Resumo: Este artigo busca analisar o panorama da indústria farmacêutica brasileira pensando a implementação do novo padrão tecnológico. A hipótese considerada é que as dificuldades na implantação da indústria avançada no Brasil podem fragilizar o setor farmacêutico nacional, abrindo espaço para o desenvolvimento de novos estudos. Através de levantamento bibliográfico descritivo serão apresentadas uma breve discussão da trajetória inovativa do setor farmacêutico, e a manufatura avançada, para que possa ser feita uma relação entre ambas. É estabelecido um paralelo entre as principais estratégias mundiais e as ações promovidas pelo Brasil para a implementação da indústria 4.0, com enfoque nas medidas direcionadas ao Setor Saúde e consequente levantamento de discussões pertinentes. Será mostrado porque o Brasil não dispõe de uma estratégia nacional de inovação de longo prazo e o consequente prejuízo para enfrentar os desafios impostos pelas inovações disruptivas.

Palavras-chave: Indústria 4.0. Políticas Industriais. Indústria farmacêutica.

Abstract: This paper evaluates the panorama of the Brazilian pharmaceutical industry thinking the implementation of the new technological standard. The hypothesis considered is that the difficulties in the implantation of the advanced industry in Brazil can weaken the national pharmaceutical sector, opening space for the development of new studies. Through a descriptive bibliographical survey will be presented a brief discussion of the innovative trajectory of the pharmaceutical sector, and advanced manufacturing, so that a relationship can be made between both. A parallel is established between the main global strategies and the actions promoted by Brazil for the implementation of industry 4.0, focusing on the measures directed to the health sector and consequent collection of relevant discussions. It will be shown why Brazil does not have a long-term national innovation strategy and the consequent loss to face the challenges posed by disruptive innovations.

Keywords: Industry 4.0. Industrial Policies. Pharmaceutical Industry.

ÁREAS ABEIN: 5.7 - Inovação, competências e competitividade

Classificação Journal Economic Literature (JEL): 033.

\footnotetext{
1 Professor Associado da Universidade Federal da Bahia (UFBA) / Coordenador e Pesquisador da Unidade de Estudos Setoriais (UNES-UFBA), Salvador, BA, Brasil. E-mail: hamijr@ufba.br.

2 Professora Efetiva da Universidade Estadual de Goiás (UEG) / Doutoranda do Programa de Pós-Graduação em Economia da Universidade Federal da Bahia (UFBA) / Pesquisadora da Unidade de Estudos Setoriais (UNES-UFBA), Salvador, Ba, Brasil. Email: inaraamorim@gmail.com.

${ }^{3}$ Doutora em Economia Aplicada pela Universidade Federal da Bahia (UFBA) / Pesquisadora da Unidade de Estudos Setoriais (UNES-UFBA), Salvador, Ba, Brasil. Email: ivanessatnc@gmail.com.

${ }^{4}$ Doutoranda do Programa de Pós-Graduação em Economia da Universidade Federal da Bahia (UFBA) / Pesquisadora da Unidade de Estudos Setoriais (UNES-UFBA), Salvador, Ba, Brasil. Email: joanafr1@gmail.com.
} 


\section{1 - INTRODUÇÃO}

Nos anos 90 a reestruturação global da indústria foi condicionada em grande medida pelas estratégias de internacionalização e de gestão da cadeia de produção e de valor das grandes empresas transnacionais (ETN), fato que promoveu um forte deslocamento do processo produtivo e redirecionou os fluxos globais de produção, de investimento e de comércio exterior (SARTI; HIRATUKA, 2010).

O processo induziu a fragmentação geográfica da produção de várias cadeias de valor, com destaque para as indústrias de equipamentos de tecnologia da informação, componentes, bens de capital, automobilística, incluindo o setor farmacêutico. As empresas multinacionais dos países avançados fragmentaram a produção para os países em desenvolvimento.

Com o passar do tempo, as indústrias asiáticas (em destaque as chinesas e as sul coreanas) automatizaram os processos, investiram maciçamente em $\mathrm{P} \& \mathrm{D}$, difundiram novas marcas nos mercados domésticos e partiram para disputar a liderança mundial com as grandes empresas ocidentais.

Após a crise financeira de 2008, e pressionados pela forte ascensão da Coreia do Sul e da China, os países industriais avançados reagiram adotando estratégias de inovação mais arrojadas, ampliando seus dispêndios privados e públicos em ciência, tecnologia e inovação. Ganhou corpo nos últimos anos uma verdadeira corrida tecnológica entre os principais países industriais ocidentais e asiáticos, e a retomada da formulação de Políticas Industriais promulgadas pelo Estado (CHERIF; HASANOV, 2019).

A Alemanha se torna o país pioneiro cunhando o termo indústria 4.0, seguido pelos Estados Unidos (EUA), onde esse processo é conhecido como Advanced Manufacturing, ou manufatura avançada. Para a Alemanha esse esforço tem por intuito de manter a liderança europeia em máquinas, produção e patentes, e ter o pioneirismo em padrões e pesquisas sobre o tema. Para os EUA a estratégia é impulsionar o crescimento econômico revertendo parte da migração de suas indústrias para países com mão de obra mais barata (ALCANTARA; NEVES, 2016).

Neste aspecto, podemos identificar que outros países estão avançando rápido na robotização e digitalização de suas indústrias, como é o caso da China (China Manufacturing 2025), França (Industrie du Futur), Japão (Society 5.0). Por conta da busca por um novo paradigma tecnológico o movimento pode ser apresentado como a Quarta Revolução Industrial (ARBIX ET AL, 2018).

Os projetos para a implantação e consolidação do novo paradigma contemplam setores estratégicos da economia mundial, como o farmacêutico. A indústria farmacêutica é singular em alguns aspectos. No mundo, é uma indústria altamente intensiva em ciência e conhecimento (PAVITT, 1984; HATZICHRONOGLOU, 1997; GALINDO-RUEDA; VERGER, 2016), cujo valor em vendas já ultrapassa US\$ 1 trilhão. Por meio de elevados investimentos em pesquisa e desenvolvimento (P\&D), gera e difunde conhecimento científico, além de contribuir para a formação de recursos humanos altamente qualificados. Ademais, a alta agregação de valor de seus produtos, é capaz de contribuir para o crescimento econômico e para a geração de divisas e melhoras nos termos de troca dos países. Por estar relacionada à saúde e ter forte impacto social (CNI, 2018).

Segundo o Sindicato das Indústrias Farmacêuticas no Estado de São Paulo (Sindusfarma), em 2018, o EUA possuiu a maior parcela em termos de vendas globais, já o Brasil consolidou-se na oitava posição. Para o sindicato, até o ano de 2021, projeta-se que o Brasil ocupe a quinta posição em termos de participação de mercado.

Cabe ressaltar que, apesar da relevância nas vendas, a indústria farmacêutica brasileira é composta por divisões de empresas multinacionais, focadas nas etapas de menor valor agregado, por empresas nacionais pouco capitalizadas e com pouca capacidade de inovação, e, por um pequeno grupo de empresas e biotecnologia (TEIXEIRA, 2014). Isto porque, segundo Achilladelis e Antonakis (2001), as atividades inovadoras estão concentradas em poucos países desenvolvidos - EUA, Reino Unido, Alemanha, Suíça e França -, que contam com um ambiente institucional favorável para a produção de inovações na fronteira tecnológica.

À luz das estratégias para a implementação do novo padrão tecnológico, o artigo objetiva analisar o panorama da indústria farmacêutica brasileira. A hipótese é que as dificuldades da implantação da indústria 4.0 no Brasil possa fragilizar o setor farmacêutico nacional, abrindo espaço para o desenvolvimento de novos estudos. A metodologia embasa-se no levantamento bibliográfico descritivo. 
Para além da parte introdutória e as considerações finais, o texto está organizado da seguinte maneira: na seção dois são apresentados os conceitos e o novo panorama da indústria 4.0, como um todo. $\mathrm{Na}$ seção três, são elucidadas as principais estratégias de políticas internacionais, comparando-as com as ações promovidas no Brasil para a implementação da indústria 4.0, especialmente, direcionadas ao setor da saúde. Posteriormente, na seção quatro é apresentada uma breve discussão da trajetória inovativa do setor farmacêutico e a caracterização da indústria farmacêutica nacional, enfatizando os gargalos estruturais que limitam a expansão do setor a partir da fronteira de inovação.

Por último, debate-se a realidade do setor, apontando para a não eficiência do sistema de inovações do país. Em adição, orientações são propostas para a implementação de uma política industrial que aproveita as vantagens disruptivas impostas pelo novo paradigma tecnológico.

\section{2 - A MODERNIZAÇÃO DA INDÚSTRIA NO SÉCULO XXI}

A Primeira Revolução Industrial, iniciada na Europa no final do século XVIII, introduziu as facilidades da produção mecânica, sobretudo com a criação da máquina a vapor, tornando obsoleta a manufatura artesanal que vigorava até então. A partir dos anos de 1870, a eletricidade, o surgimento das linhas de montagem e a divisão do trabalho derivada do Taylorismo levaram à $2^{\mathrm{a}}$ Revolução. Já a $3^{\mathrm{a}}$, também conhecida como Revolução Digital, teve início na década de 1970 e foi impulsionada pelo emprego das primeiras tecnologias de informação que desenvolveram, ainda mais, a automação dos meios de produção (TESSARINI; SALTORATO, 2018).

Schwab e Davis (2018) relatam que as tecnologias emergentes da Quarta Revolução Industrial são construídas sobre o conhecimento e os sistemas das outras revoluções, em particular, sobre recursos digitais da Terceira Revolução Industrial. Sendo assim, a indústria 4.0 é a utilização de um conjunto de tecnologias digitais como internet das coisas, computação em nuvem, realidade aumentada, big data, manufatura aditiva, robôs colaborativos, integração de sistemas e segurança cibernética, de forma isolada ou em conjunto, nos processos produtivos ou cadeias de serviços. A adoção das tecnologias cria um ambiente ciber-físico, em que máquinas e sistemas conversam entre si para tornar linhas de produção autônomas, flexíveis e customizáveis, gerando maior produtividade e eficiência. Para além das linhas de produção, do tratamento de câncer ao desenvolvimento de carros sem motorista, de algoritmos que negociam ações a supermercados que dispensam caixas, os campos de aplicação das novas tecnologias são promissores.

Como descreve Labrunie (2018) a Inteligência Artificial (IA) é um conjunto de tecnologias computacionais que são inspiradas nas formas como os humanos usam seus sistemas para sentir, aprender, raciocinar e agir. As principais inovações disruptivas são o machine learning, o deep learning, o processamento de linguagem natural, o reconhecimento das imagens e o data analytics.

A internet das coisas (IoT) é uma derivação do conceito de conectividade entre máquinas, expandindo-o para vários tipos de objetos que se comunicam e interagem entre si, diretamente ou indiretamente, através de sensores, softwares, etc. Assim, os objetos se tornam mais inteligentes devido a sua conectividade com sistemas de tratamentos de dados (servidores, data centers, plataformas de cloud computing, big data), ampliando a capacidade de gerar dados estruturados para análise e controle das atividades.

As tecnologias de rede servem para "costurar" as demais tecnologias digitais, recebendo dados dos sensores das IoT's, transportando informações a serem analisadas pelos sistemas de data analytics e IA, e servindo como vias de circulação de informações nos sistemas ciber-físicos da produção inteligente.

A nanotecnologia pode ser definida como a área de ciência e tecnologia que lidam com a matéria na escala nanoscópica (menos do que $100 \mathrm{~nm}$ em pelo menos uma de suas dimensões). As principais inovações disruptivas podem ser vistas na nanomedicina, nanocosméticos, nanoeletrônica e novos materiais para computação.

A biotecnologia moderna surgiu com a engenharia genética e o sequenciamento do genoma humano em 2001. Desenvolvimentos simultâneos nas áreas de bioinformática, microquímica e novos materiais permitiram avaliar a resposta do genoma ao ambiente, e na transição saúde-doença. Tal movimento possibilitou a medicina de precisão, caracterizada pela adoção de terapias baseadas no 
mecanismo molecular da doença, utilizando biomarcadores para individualização da terapia e estratificação dos pacientes.

As áreas da biotecnologia com potencial disruptivo são: genômica e medicina de precisão, engenharia genética, edição genômica e biologia sintética, medicina diagnóstica por imagem, medicina regenerativa, células-tronco e biomateriais, e-Science, aplicações de IoT para saúde e medicina individualizada.

Lobo (2017) relata o uso da interação destas tecnologias na saúde. A experiência de Sebastian Thrun, da Universidade de Stanford, proporcionou o aprendizado da inteligência artificial por meio de algoritmos a partir de uma rede neural de computação com 130 mil imagens de lesões da pele classificadas por dermatologistas. Em junho de 2015, Thrun e sua equipe começaram a validar o sistema usando um conjunto de 14 mil imagens que haviam sido diagnosticadas por dermatologistas, solicitando que o sistema reconhecesse três tipos de lesão: benignas, malignas e crescimentos não cancerosos. $\mathrm{O}$ sistema acertou $72 \%$ das vezes, comparado com um acerto de $66 \%$ obtido por dermatologistas qualificados. A experiência de Thrun foi ampliada para incluir 25 dermatologistas e uma amostra de 2 mil casos biopsiados. A máquina continuou sendo mais acurada do que o diagnóstico humano.

Outro caso de destaque, segundo reportagem do Valor Econômico ${ }^{5}$, foi apresentação em 2015 do Watson Health, um sistema de Inteligência Artificial para a saúde desenvolvido pela empresa IBM. O sistema tem a capacidade de concatenar informações, não organizadas, de uma ampla literatura médica. Foi o que ocorreu quando a empresa anunciou ter identificado cinco genes ligados à esclerose lateral amiotrófica, conhecida pela sigla em inglês ELA. A doença, de caráter degenerativo, atinge os neurônios motores e provoca atrofia muscular até a paralisação total do paciente, que não perde suas capacidades mentais ao longo do processo. Watson leu todas as publicações conhecidas sobre a doença. Depois, o pesquisador classificou quase 1,5 mil genes humanos e analisou quais deles poderiam estar associados à ELA. A IBM trabalhou com o Instituto Neurológico de Barrow, em Phoenix, nos EUA, cuja equipe avaliou que oito dos dez genes indicados estavam, de fato, ligados à doença - para cinco deles, essa associação era inédita. O processo levou meses, mas os cientistas envolvidos disseram que teriam levado anos se não fosse o sistema.

A mesma reportagem destaca que no Brasil, no ano de 2016, a empresa de diagnóstico Fleury Medicina e Saúde foi o primeiro parceiro da unidade Watson na América Latina. Com a aquisição do software Watson Genomics, a instituição tem auxílio para identificar medicamentos e ensaios clínicos relevantes com base em alterações genômicas de um indivíduo e dados extraídos de uma vasta literatura médica. O sistema utiliza pesquisas, ensaios clínicos e artigos científicos para auxiliar os médicos nas opções de tratamento aprovados mais recentes, incluindo opções de tratamento personalizados através de imunoterapia, marcadores biológicos e bancos de dados genômicos.

Nacionalmente, salienta-se também a Fundação do Cidacs - Centro de Integração de Dados e Conhecimentos para a Saúde. Um complexo de serviços, recursos físicos e humanos nas áreas de epidemiologia, estatística, bioinformática e computação, a partir da integração de grandes bases de dados (big data). O Centro inaugurado em 2016 faz parte do Instituto Gonçalo Moniz, da Fundação Oswaldo Cruz, e conta com plataformas de pesquisas que visam o aprimoramento do estudo da epidemiologia genômica e que buscam a avaliação e a oferta de soluções em saúde digital para os programas e ações do Sistema Único de Saúde.

Estas experiências apresentam áreas de pesquisa e inovação com grandes oportunidades. A demanda por trabalhadores altamente qualificados cresce, enquanto a demanda por trabalhadores com formação e habilidades menores diminui. Os países que liderarem a inovação tendem a se tornar os fornecedores de capital intelectual e físico neste novo ambiente industrial (SCHWAB, 2016).

Sendo assim, a inovação é um dos principais determinantes da produtividade e da competitividade. Os países que apresentarem uma agenda política-institucional coordenada e eficaz próinovação, tendem a ter uma inserção internacional favorável. A seguir são expostas as características da indústria 4.0.

\footnotetext{
${ }^{5}$ Disponível em: https://www.valor.com.br/cultura/4827632/admiravel-cerebro-novo.
} 


\section{3 - POLÍTICAS PARA A IMPLEMENTAÇÃO DA INDÚSTRIA 4.0 E AS DIRETRIZES PARA O SETOR DE SAÚDE: O CASO DA ALEMANHA, EUA, CHINA E BRASIL}

Especialmente após a crise subprime de 2008, a temática em torno das políticas industriais voltou a ter relevância. Esse movimento reflete as mudanças globais da produção manufatureira. De acordo com O'Sullivan e outros (2013), as mudanças foram norteadas pela queda das atividades manufatureiras dos países da OCDE, pela elevação da concorrência das economias emergentes, em destaque para as asiáticas, pela inserção dos países nas cadeias globais de valor e pelo acelerado ritmo de mudanças tecnológicas.

Dessa forma, a ação do Estado deve ocorrer mediante políticas de incentivo às atividades inovativas de suas indústrias, possibilitando, simultaneamente, tanto a construção de um ambiente institucional favorável, como a infraestrutura adequada para a promoção de interações no interior de seus sistemas nacionais (CIMOLI; DOSI; NELSON; STIGLITZ, 2007).

Em consonância com as alterações globais, a indústria farmacêutica adquiriu nova configuração, para não perder o mercado consumidor de seus produtos cujas patentes já haviam expirado, ampliou o seu portfólio, que passou a englobar desde a área de saúde animal até os produtos de higiene e de cuidado pessoal, de nutrição e de dietética. Ademais, as indústrias farmacêuticas dos países desenvolvidos mantiveram nas suas matrizes a concentração em pesquisa e desenvolvimento, e verticalizaram a produção de medicamentos. Na maioria das vezes, elas transferiram essa produção, o marketing e a comercialização desses insumos para os países em desenvolvimento (KORNIS et al, 2014).

Segundo os autores, neste contexto, a indústria farmacêutica nos países desenvolvidos passou a se concentrar nas inovações em P\&D e no desenvolvimento de medicamentos biotecnológicos. Estados Unidos, Alemanha, Suíça e Reino Unido constituíram os principais produtores de biotecnológicos, sendo que em 2010, nos EUA, esses produtos representaram 44\% das vendas totais da indústria.

Sendo assim, enquanto os mercados desenvolvidos destacam pela produção de medicamentos de fronteira tecnológica, em um ambiente institucional propício a inovação, a indústria farmacêutica brasileira é basicamente dedicada ao desenvolvimento, produção e comercialização de produtos genéricos e similares a partir de princípios ativos importados (URIAS, 2009).

A divergência aprofunda-se à medida que analisamos as políticas industriais que norteiam a implantação dos pilares da manufatura avançada entre os países selecionados. A partir de uma compilação dos trabalhos desenvolvidos por Labrunie (2018) e Arbix e outros (2018), descreve-se o arranjo, com foco no setor de saúde, das políticas delineadas na Alemanha, Estados Unidos, China e Brasil.

\section{Alemanha}

De acordo com Arbix e outros (2018), em 2015, a Indústria 4.0 seria incluída oficialmente nos programas oficiais de governo alemão, graças à intensa movimentação de empresários, empresas, universidades, centros de pesquisa e associações de classe. Por conta da origem desburocratizada, o sistema de governança transformou-se em um de seus pontos distintivos, precisamente por estimular o diálogo e contemplar a diversidade da sociedade civil. Após sua consolidação como política oficial de governo, a Industrie 4.0 passou a ocupar posição central nos planos da Alemanha e foi integrada à política de inovação mais importante do governo, a Die Neue Hightech-Strategie (A Nova Estratégia High-Tech, relançada em 2014), e à Digitale Strategie 2025 (Estratégia Digital 2025).

A Nova Estratégia High-Tech, matriz da política industrial alemã, definiu dez projetos para o futuro e incluiu a plataforma Industrie 4.0 entre suas prioridades: (i) cidades com eficiência energética e balanço neutro em emissões de $\mathrm{co}_{2}$; (ii) biomassa como alternativa ao petróleo; (iii) conversão inteligente de fontes de energia; (iv) tratamentos médicos personalizados; (v) saúde preventiva e alimentação; (vi) envelhecimento e vida independente; (vii) mobilidade sustentável; (viii) internet para a economia; (ix) industrie 4.0; (x) identificação segura.

Essas políticas procuram acelerar a transferência de conhecimento científico para produtos, processos e serviços e aperfeiçoar o ambiente de inovação com o objetivo de manter a Alemanha na liderança mundial em inovação industrial. Nota-se que a ênfase dada no setor de saúde é focalizada nos tratamentos médicos personalizados e na saúde preventiva através da interação das novas tecnologias. 


\section{Estados Unidos}

Nas décadas mais recentes, a participação da manufatura como parcela geradora do Produto Interno Bruto e do emprego vem declinando nos segmentos de baixa e alta intensidade tecnológica.

A política norte-americana está baseada fundamentalmente em produtos de tecnologia avançada. O plano estratégico incorpora intensivo engajamento entre participantes da indústria, trabalho, academia e do governo, aos níveis nacional, estadual e regional, bem como políticas para pesquisa e desenvolvimento.

No relatório de 2014, são mencionados quatro pilares sobre os quais a política se sustenta: (i) estabelecer uma Estratégia Nacional para Tecnologia Industrial; (ii) estabelecer e apoiar a National Network for Manufacturing Innovation (NNMI), posteriormente chamado de Manufacturing USA; (iii) capacitação dos talentos; (iv) melhorar o ambiente de negócios ao aumentar o acesso ao capital para firmas estabelecidas e startup.

Em adição, no relatório americano de 2016, são mencionadas as áreas prioritárias de política, divididas em áreas emergentes e áreas de prioridade existentes. No campo da saúde, destacam-se como áreas prioritárias: robótica assistiva e Soft Robotics e bioengenharia para a medicina regenerativa; engenharia biológica para biomanufatura; e produção contínua de fármacos (LABRUNIE, 2018).

Segundo Labrunie (2018), houve a criação de uma rede de institutos de pesquisa voltados para a indústria 4.0 (manufatura avançada), chamada de Manufacturing USA. Atualmente, há 14 institutos estabelecidos, cada um focado em uma área tecnológica crítica, e fala-se em expandir para 45 institutos em 10 anos. Outras iniciativas importantes para tecnologias são a National Nanotechnology Initiative (NNI), o Manufacturing Technology Program (ManTech), e a MaterialsGenomeInititative. Para as pequenas e médias empresas, incluindo startups, há o programa Manufacturing Extension Partnership (MEP), o Small Business Innovation Research (SBIR), o Small Business Technology Transfer (STTR) e o America's Seed Fund.

\section{China}

Arbix e outros (2018) apontam o alinhamento do governo chinês pelas grandes empresas estatais aos seus planos estratégicos. Instituições, mecanismos e recursos públicos estão direcionados às áreas e segmentos definidos pelos planos de governo. Em geral, três planos se destacam.

A gama de políticas que a China mobiliza para desenvolver tecnologias avançadas é ampla e diversificada. O governo opera com planos quinquenais, que definem objetivos, prioridades, metas, instrumentos, investimentos e critérios de avaliação. Atualmente a China implementa seu $13^{\circ}$ Plano Quinquenal, elaborado para o período de 2016 a 2020, e que definiu as seguintes prioridades: (i) inovação como estratégia para se alcançar o desenvolvimento econômico e social; (ii) apoio ao desenvolvimento da indústria 4.0; (iii) foco nas indústrias emergentes, dentre as quais biotecnologia, indústria de baixo carbono, tecnologias da informação e novos materiais; e nas estratégicas, como aeroespacial, nuclear e ciências da vida.

Segundo os autores, além do Plano Quinquenal, o país possui o Programa de Médio e Longo Prazo para o Desenvolvimento da Ciência e Tecnologia 2006-2020 (MLP 2006-2020), que tem um horizonte de quinze anos e abrange três Planos Quinquenais. O MLP 2006-2020 é um marco no processo de construção de uma agenda política pró-inovação na China, com estaque para: (i) meta de $2,5 \%$ do Produto Interno Bruto investidos em pesquisa e desenvolvimento; (ii) elevação para mais de $60 \%$ a contribuição das tecnologias avançadas para o crescimento econômico; (iii) limitação em até 30\% a dependência da China de tecnologias importadas; (iv) despontar entre os cinco maiores países em depósito de patentes de residentes; (v) assegurar que a produção científica chinesa esteja entre as mais citadas no mundo.

Arbixet al (2018) relatam que o governo chinês ampliou suas iniciativas em direção à indústria 4.0 com o plano Made in China 2025 (MiC 2025), lançado em 2015. O plano procura responder aos desafios domésticos e preparar a China para as novas indústrias que se desenvolvem no plano internacional. $\mathrm{O}$ plano colocou no centro de suas preocupações a digitalização e a automação, que prometem profundas mudanças na manufatura, conforme anunciadas na Alemanha com a plataforma Indústria 4.0. Para realizar esses objetivos foram definidas cinco diretrizes: 
1. Promover a inovação, motor do desenvolvimento;

2. Melhorar a qualidade dos produtos e serviços disponíveis no mercado;

3. Tornar a economia mais sustentável;

4. Otimizar a estrutura industrial;

5. Incentivar a formação e a qualificação dos recursos humanos e a retenção de talentos.

Labrunie (2018) afirma que no setor de saúde o objetivo chinês é desenvolver biofármacos e equipamentos médicos de alta performance.

\section{Brasil}

Nacionalmente, o Projeto Indústria $2027^{6}$ apresenta-se como um documento inicial com o objetivo de avaliar os impactos de um conjunto de tecnologias emergentes e com alto potencial transformador sobre a competitividade industrial no horizonte de até 10 anos, além de fornecer subsídios para o planejamento de empresas e a formulação de políticas.

Os resultados revelam um panorama preocupante e desafiador. A posição do país está longe de ser confortável nessa corrida tecnológica. Em uma amostra representativa de 759 grandes e médias empresas consultadas em uma pesquisa de campo, apenas $1,6 \%$ considera operar na fronteira tecnológica, a chamada Indústria 4.0, ou seja, com processos fabris integrados, conectados e inteligentes. Cerca de $21,8 \%$ dessas empresas afirmam querer chegar a esse patamar até 2027, o que exigirá financiamento a $\mathrm{P} \& \mathrm{D}$, mudanças organizacionais e apoio de políticas públicas.

No que tange o setor farmacêutico nacional seu avanço converge para o desenvolvimento de atividades de síntese química e biotecnológica. Contudo, isto impõe desafios que são intensificados, quando observa a formação da nova onda de convergência tecnológica e de frentes de pressão de demanda com potencial de impacto disruptivo. Assim, os avanços na biologia molecular, nas ciências "ômicas", na bioinformática, nos biomarcadores, nas engenharias genética e genômica, nos algoritmos de inteligência artificial (com ou sem utilização de big data) aplicados ao P\&D farmacêutico, podem representar ameaças para a indústria brasileira nos próximos dez anos (CNI, 2018).

Segundo o Projeto Indústria 2027, o avanço da biotecnologia tem um poder disruptivo no setor farmacêutico brasileiro. Ou seja, as mudanças promoverão significativas modificações no modelo de negócio, padrões de concorrência e possivelmente nas estruturas de mercado no médio prazo. Sendo assim, caráter disruptivo não diz respeito à radicalidade das inovações envolvidas, mas sim a descontinuidades promovidas a partir da conjunção do uso de diferentes tecnologias existentes (FIGURA $1)$.

Figura 1 - Perspectivas dos impactos dos avanços tecnológicos no setor farmacêutico brasileiro entre 2017 e 2027

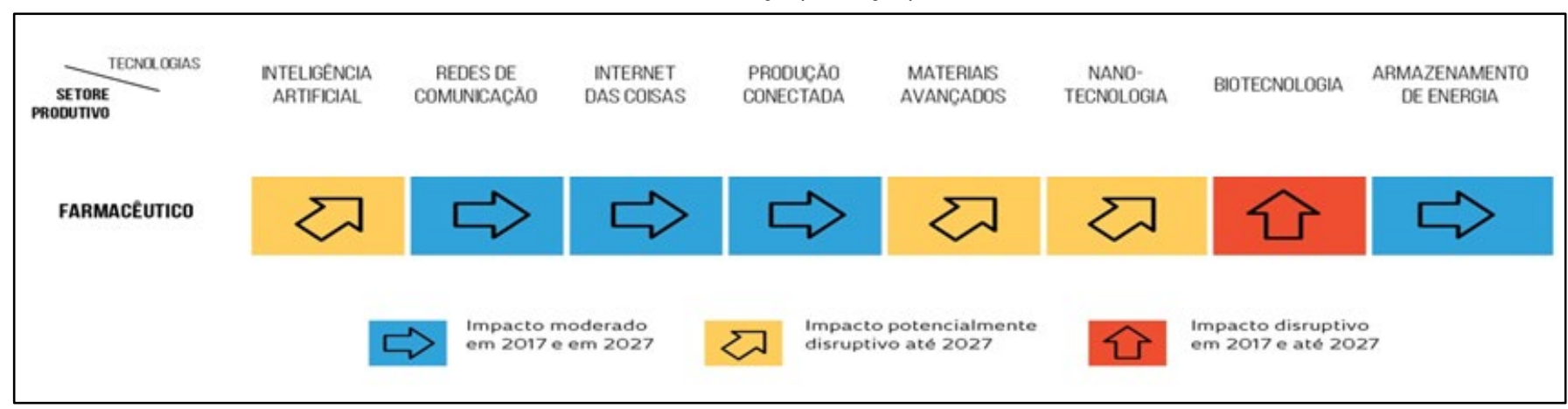

Fonte: CNI (2018).

A perspectiva é que os avanços na inteligência artificial, nos materiais avançados e na nanotecnologia apresentem um alto potencial disruptivo, enquanto as redes de comunicação, internet das coisas, produção conectada e armazenamento de energia, tenham um impacto moderado no setor. Para

\footnotetext{
${ }^{6}$ Projeto publicado em 2018 elaborado com a iniciativa da Confederação Nacional da Indústria (CNI) com execução técnica do Instituto de Economia da Unicamp e da UFRJ e realização do Instituto Euvaldo Lodi.
} 
tanto, o Quadro 1 apresenta a descrição dos impactos disruptivos e com potencial disruptivo para a produção farmacêutica.

Quadro 1 - Impactos disruptivos e potencialmente disruptivos para a indústria farmacêutica

\section{Biotecnologia}

Diagnósticos através de marcadores genômicos;

Prognósticos específicos e individualizados;

Novas moléculas (drogas) específicas para cada tipo de doença;

Previsão das respostas aos medicamentos por biomarcadores genéticos (variações genoma);

Engenharia genética, edição genômica e biologia sintética, e

Terapias celulares (medicina regenerativa, células-tronco).

\section{Inteligência artificial}

Machine learning: medicina personalizada, alocação de recursos, fixação preços.

Deep learning no desenvolvimento de novos medicamentos, análises de patentes (algoritmos de GAN).

\section{Materiais avançados}

Filmes e géis poliméricos para a liberação controlada de fármacos;

Sensores, sistemas de TIC e materiais para controle de dosagem de medicamentos;

Implantes ativos contendo fatores de crescimento, antiinflamatórios e outros.

\section{Nano-tecnologia}

Biofármacos: microorganismos ou células modificadas geneticamente;

Fitomedicamentos;

Terapia gênica: uso de genes normais para substituir genes defeituosos;

Terapia fotodinâmica, termoterapia, imunoterapia;

Órgãos artificiais, pele artificial e engenharia de tecidos.

Fonte: Elaboração própria com base no CNI (2018).

Neste contexto, nota-se que enquanto Estados Unidos, Alemanha e China estão articulando suas estratégias a partir de políticas públicas específicas e bem coordenadas, o Brasil ainda não possui ações efetivas que definam a inserção da estrutura industrial nacional no novo paradigma tecnológico. O cenário nacional se agrava, quando é considerado o ambiente macroeconômico no ano de 2019. Caracterizado por baixo crescimento econômico e elevado desemprego, juntamente com cortes significativos nos recursos financeiros destinados à ciência e tecnologia podem se traduzir em uma perda significativa de capacidade inovativa ${ }^{7}$.

\section{4 - UMA BREVE ANÁLISE DA INDÚSTRIA FARMACÊUTICA BRASILEIRA}

O sistema produtivo farmacêutico é um setor concentrado, intensivo em conhecimento, no qual as empresas líderes buscam vantagem competitiva com o lançamento de novos produtos (VARGAS et al, 2010). Para uma apresentação mais coerente, mostra-se as diretrizes da Indústria Farmacêutica no Mundo e, em especifico no caso brasileiro.

Sendo assim, nos sub tópicos seguintes é apresentado as trajetórias inovativas na Indústria Farmacêutica frente ao mercado internacional, com os principais competidores, e aquilo que é desenvolvido no Brasil, com base na composição da indústria nacional.

\footnotetext{
${ }^{7}$ https://www1.folha.uol.com.br/ciencia/2019/05/projetos-sao-cancelados-sem-aviso-e-cientistas-temem-apagao.shtml. https://jornal.usp.br/atualidades/metade-dos-pos-graduandos-do-pais-nao-recebe-auxilio-pesquisa/.
} 


\section{1 - TRAJETÓRIAS INOVATIVAS NA INDÚSTRIA FARMACÊUTICA}

A inovação tecnológica é um processo dinâmico tanto por catalisar a interação entre a ciência e a tecnologia acelerando simultaneamente seus avanços, como o próprio desenvolvimento tecnológico e a expansão dos setores industriais. Combinados, os efeitos da inovação tecnológica podem descrever a evolução histórica e econômica de indústrias intensivas em pesquisa e desenvolvimento como a farmacêutica (LANDAU et al, 1999).

Cohen e Levinthal (1990) apresentam duas funções principais da P\&D. A primeira é a criação de conhecimentos novos, objetivando a geração de inovações. A segunda é a ampliação da capacidade de absorção do conhecimento externo pelas empresas. Eles alegam que quanto mais P\&D realizado internamente, maior a habilidade de a empresa identificar, assimilar e explorar o conhecimento existente no ambiente no qual está inserida. Um grande estímulo à realização de investimentos nas atividades de P\&D é aumentar a probabilidade de absorver conhecimento externo, e assim, aumentar a capacidade inovativa da empresa; mas, para que isso ocorra, os investimentos devem ser contínuos (TEIXEIRA, 2014).

Acerca da dinâmica da inovação tecnológica na indústria farmacêutica, as empresas desenvolveram sucessivas gerações de medicamentos, e algumas poucas grandes empresas multinacionais focaram na inovação de produto. As que inovaram, moldaram suas estratégias a partir de elevados níveis de investimentos em $\mathrm{P} \& \mathrm{D}$, concentração vertical e diversificação horizontal. Praticamente, todos os grandes avanços tecnológicos durante o século XX foram incorporados por capacitações in house: da fermentação para a química orgânica e para a engenharia molecular (RADAELLI, 2012).

O pioneiro trabalho de Achilladelis e Antonakis (2001) identificou cinco ondas de inovações ou de trajetórias tecnológicas na indústria farmacêutica de natureza radical e incremental ao longo de quase dois séculos de consolidação.

No final do século XIX, o setor farmacêutico mundial começou a se organizar, tendo como fundamento a revolução química. Segundo Achilladelis e outros (1990), nos anos de 1820-1880 surgiram, no continente europeu, as inovações farmacêuticas de primeira geração, introduzidas pelo pesquisador Lavoisier e pela Escola Francesa de Química.

As inovações de segunda geração foram realizadas pelos laboratórios públicos de pesquisa médica, a fim de produzir soros e vacinas, e pelas indústrias alemãs, francesas e suíças, com experiência em química orgânica. A partir dos anos de 1930, até 1960, a indústria farmacêutica mundial passou pela terceira geração de inovação, que conduziu ao isolamento e à síntese de vitaminas, corticosteroides, hormônios sexuais e antibacterianos.

Como afirma Achilladelis (1993), após 1945, com o término da Segunda Guerra Mundial, ocorreu a explosão farmacológica e o surgimento da indústria farmacêutica norte-americana, a qual herdou os espólios do setor farmacêutico alemão, com foco na síntese química. Nessa perspectiva, no pós-guerra o setor farmacêutico mundial se consolidou e deu início à produção em massa, com consequente diversificação da oferta e da demanda por medicamentos.

A tomada da liderança pelos Estados Unidos é resultante de episódios econômicos e históricos específicos e de intervenção governamental seletiva no sentido de promover investimento privado em $\mathrm{P} \& \mathrm{D}$, de modo que a indústria dos Estados Unidos foi se conformando não só pela atuação e reposicionamento das empresas, sobretudo aquelas de origem química, como também pela ação das universidades, de ações deliberadas do governo e das autoridades regulatórias e de inspeção (RADAELLI, 2012).

Com o aumento das inovações, o mercado farmacêutico passou a ser concentrado, passando de uma competição mais ampla para uma estrutura de mercado oligopolista. A indústria farmacêutica constitui um caso de oligopólio diferenciado, mas em que a competição e a diferenciação de produto não se dão ao nível da indústria como um todo, mas de classes terapêuticas. Esses oligopólios alcançaram a liderança do mercado farmacêutico mundial por meio dos medicamentos campeões de vendas, os

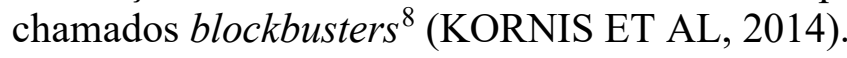

\footnotetext{
${ }^{8}$ Medicamentos que somam mais de US\$ 1 bilhão por ano em vendas.
} 
Nos anos 1980, teve início o último ciclo de inovação do setor farmacêutico mundial, que, como afirmam Achilladelis e Antonakis (2001), fundamentou-se na descoberta da biotecnologia, com ênfase na síntese do ácido desoxirribonucleico (ADN) recombinante e nos métodos de obtenção de anticorpos monoclonais, a fim de produzir proteínas fisiológicas usadas na terapia ou no diagnóstico de várias doenças.

De acordo com Radaelli (2012), o surgimento das empresas biotecnológicas como um ator adicional no campo da indústria farmacêutica é condição imprescindível para compreender as bases de conhecimento correntes. As empresas de biotecnologia surgiram como um caso de micro e pequena empresa. Como as grandes farmacêuticas possuíam dificuldades em internalizar conhecimento oriundo das novas técnicas e das novas tecnologias de forma rápida, as novas e pequenas empresas passaram a ocupar o papel de tradutores de conhecimento novo nos estágios iniciais de pesquisas baseadas em tecnologias incipientes. As possibilidades econômicas vislumbradas com o funcionamento de organismos vivos como o do sequenciamento genético modificaram por completo o regime de conhecimento na pesquisa farmacêutica numa infinidade de caminhos.

Segundo a autora, as técnicas incorporadas pela biotecnologia se caracterizavam pela interdisciplinaridade de conhecimentos complementares (biologia, química, materiais, mecânica, robótica, fornecedores de equipamentos, indústrias de computadores e de softwares). O aprendizado em trabalhar de forma interdisciplinar impulsionou a descoberta de novas atividades industriais, novos métodos e novas técnicas, novos instrumentos, novos equipamentos, novas aplicações e soluções de informática.

Neste novo cenário, as empresas de biotecnologia passaram a ter outro papel, passando de tradutores para exploradoras de oportunidades científicas e tecnológicas das grandes empresas farmacêuticas.

Nos anos 2000, as fronteiras tecnológicas continuaram a ser pressionadas. No campo das ciências biológicas, a biologia molecular, a genômica e a proteômica continuaram avançando. A engenharia genética vem ampliando seu alcance e, atualmente, já é possível conceber a ideia de "reparos" e "melhorias" genéticas por meio de técnicas da chamada engenharia genômica. Novas tecnologias da informação relacionadas à pesquisa em saúde, como a bioinformática e a inteligência artificial, também são elementos de uma possível nova frente de convergência tecnológica (CNI, 2018).

A utilização do conjunto de tecnologias digitais e o ramo da biotecnologia apresenta-se como a nova fronteira tecnológica a ser atingida pelos países. Assim, a quinta onda de inovação na indústria farmacêutica apresenta-se vinculada a Quarta Revolução Industrial em curso a partir do início do século XXI.

\section{2 - CARACTERIZAÇÃO E DESAFIOS DA INDÚSTRIA FARMACÊUTICA BRASILEIRA;}

Segundo a CNI (2018), em 2014, as maiores empresas de produtos farmacêuticos investiram em média $15 \%$ de suas receitas líquidas em P\&D e as vendas mundiais deste setor ultrapassaram a marca de US\$ 1 trilhão, e em 2017, situaram-se acima de US\$ 1,10 trilhão.

Os Estados Unidos são o maior mercado, responsáveis por aproximadamente metade das vendas globais enquanto o Brasil é o sexto maior. A partir da Tabela 1 são observadas as dez maiores empresas de produtos farmacêuticos sob prescrição no ano de 2015. Nota-se que há maior presença de empresas norte americanas, com percentual expressivo das receitas dos fármacos sob prescrição no faturamento. Vê-se ilustrado, também, o nível de investimentos dessas empresas em P\&D.

Os EUA têm quatro empresas no ramo farmacêutico entre as dez maiores empresas do mundo no ano de 2015, totalizando um faturamento de cerca de US\$ 190 bilhões; seguido da Suíça e do Reino Unido, cada país com duas empresas no segmento, com US\$ 99,525 bilhões e US\$ 60,207 bilhões, respectivamente. França e Alemanha também possuem uma empresa entre as dez maiores, com faturamento de US\$ 34,542 bilhões e US\$ 51,407 bilhões, respectivamente.

Como exposto, na Tabela 1, os EUA são o país que mais investem em $\mathrm{P} \& \mathrm{D}$, tendo na empresa Johnson \& Johnson o maior resultado, 10,0. A Suíça também emprega tecnologia e pesquisa nas suas empresas, sendo a Hoffmann-La Roche AG, com 9,97 e a Novartis AG, com 8,94, figurando a segunda e a terceira empresa do mundo que investe em P\&D. 
Tabela 1 - Maiores empresas de produtos farmacêuticos sob prescrição em 2015 - Bilhões US\$

\begin{tabular}{clccc} 
Ranking & \multicolumn{1}{c}{ Fabricante } & Faturamento & $\begin{array}{c}\% \text { das receitas dos } \\
\text { fármacos no } \\
\text { faturamento }\end{array}$ & $\begin{array}{c}\text { Investimento } \\
\text { em P\&D }\end{array}$ \\
\hline 1 & Johnson \& Johnson (EUA) & 70,074 & $44,8 \%$ & 10,00 \\
2 & Hoffmann-La Roche AG (Suíça) & 50,111 & $77,5 \%$ & 9,97 \\
3 & Pfizer Inc. (EUA) & 48,851 & $27,1 \%$ & 7,69 \\
4 & Novartis AG (Suíça) & 49,414 & $31,1 \%$ & 8,94 \\
5 & Bayer AG (Alemanha) & 51,407 & $33,7 \%$ & 8,00 \\
6 & Merck \& Co., Inc. (EUA) & 39,498 & $88,1 \%$ & 6,70 \\
7 & Glaxo S. Kline plc (Reino Unido) & 36,566 & $21,5 \%$ & 5,44 \\
8 & Sanofi (França) & 34,542 & $29,0 \%$ & 5,09 \\
9 & Gilead Sciences, Inc. (EUA) & 32,639 & $55,4 \%$ & 3,01 \\
10 & Astra Zeneca plc (Reino Unido) & 23,641 & $46,1 \%$ & 5,99 \\
\hline
\end{tabular}

Fonte: Forbes (2016).

Os competidores de capital estrangeiro estabeleceram no Brasil capacidades produtivas relacionadas a fármacos já em estágio avançado no ciclo de vida. Medicamentos mais modernos e complexos vêm sendo comercializados por meio de importações, visto que na grande maioria dessas empresas não existem atividades de $\mathrm{P} \& \mathrm{D}$ locais integradas às suas estratégias globais.

Tessarin e outros (2019) corroboram ao evidenciar que os investimentos em P\&D feitos por empresas estadunidenses da indústria de transformação que atuam dentro do seu país são bem maiores do que daquelas que atuam fora dele, especialmente nos setores de alta tecnologia. Para a indústria de transformação, essa diferença é de três vezes, e esse comportamento se replica para todos os demais setores manufatureiros e por categorias de intensidade tecnológica. Para o setor farmacêutico o percentual médio entre 2009 e 2015, dos dispêndios em P\&D em relação às vendas efetuadas pelas empresas dos EUA encontra no patamar de $15,06 \%$ quando localizadas dentro do território americano. A razão reduz para 3,60\% quando localizadas fora do território americano e para quase zero nas corporações situadas no Brasil.

Segundo Vargas e outros (2012), em termos gerais, o panorama atual da indústria de base química e biotecnológica em saúde no Brasil pode ser sintetizado a partir dos seguintes pontos:

- o Complexo Econômico Industrial da Saúde (CEIS) como um todo e a indústria de base química e biotecnológica em particular contam com elevada participação relativa no produto interno bruto, no valor agregado industrial e no emprego qualificado do Brasil, mas também respondem por uma participação elevada no déficit da balança comercial do País;

- a análise da estrutura produtiva ainda revela importantes gargalos estruturais na cadeia produtiva, sobretudo na produção de fármacos (insumos farmacêuticos ativos);

- a retomada recente no crescimento do setor farmacêutico, fomentada pela expansão do mercado de genéricos, viabilizou o fortalecimento das empresas farmacêuticas nacionais, mas também tem constituído um forte estímulo para a entrada dos grandes laboratórios farmacêuticos multinacionais no mercado brasileiro por meio da aquisição de empresas locais;

- as empresas do setor farmacêutico no Brasil ainda apresentam investimentos reduzidos em atividades inovativas e de pesquisa e desenvolvimento (P\&D), tanto em termos do padrão internacional da indústria farmacêutica como em relação aos setores mais dinâmicos da indústria brasileira;

- a estrutura produtiva em saúde no Brasil conta com o papel destacado desempenhado pelos laboratórios oficiais na Política Nacional de Saúde, na produção de medicamentos para o Sistema 
Único de Saúde (SUS), no suporte à regulação ou no processo de ampliação da capacitação tecnológica nacional;

- elevada concentração da estrutura produtiva da indústria farmacêutica nas regiões Sul e Sudeste, particularmente nos estados de São Paulo, Rio de Janeiro e Minas Gerais;

- forte assimetria da concentração da estrutura produtiva industrial na distribuição da infraestrutura científica e tecnológica ligada ao esforço de pesquisa, desenvolvimento e inovação em saúde.

Um dos principais reflexos da fragilidade da produção em saúde no âmbito da indústria de base química e biotecnológica no Brasil reside no crescimento acelerado do déficit na balança comercial de fármacos (princípio ativo), desde os anos 2000 (IEDI, 2018). O movimento pode ser analisado a partir do Gráfico 1.

Gráfico 1 - Evolução do déficit da Balança Comercial de Fármacos- Brasil - US\$ bilhões - 1997-2016

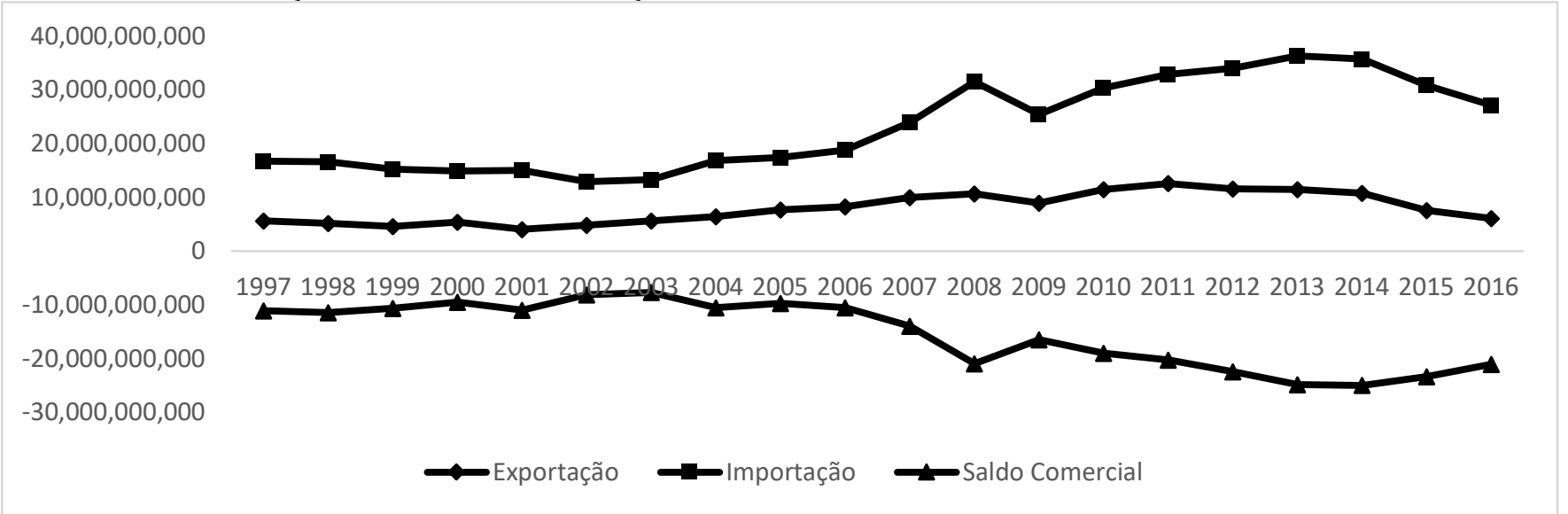

Fonte: Elaboração própria (2018), a partir dos dados coletados na Rede Alice (SECEX/MIDIC).

Para além da dependência da importação de princípios ativos, segundo a Associação da Indústria Farmacêutica em Pesquisa - Interfarma (2015) dos anos de 2005 a 2015 o Brasil importou medicamentos de 78 países. A Alemanha foi a principal origem das importações, atingindo US\$ 1,3 bilhão (19\% do total). Os Estados Unidos e a Suíça aparecem na sequência com US\$1,18 bilhão (17\%) e US\$ 811 milhões (12\%), respectivamente.

Em contrapartida, o Brasil exportou medicamentos para 169 países nos últimos dez anos, sendo que 20 destinos concentraram 92\% das exportações. A Dinamarca foi o país mais importante para as exportações brasileiras de medicamentos, representando $25 \%$ do total, com valor de US\$ 333 milhões. Quase $90 \%$ do total exportado para a Dinamarca é referente a medicamentos à base de insulinas, correspondendo a US\$ 267 milhões. Na sequência apareceram dois países do Mercosul - Venezuela e Argentina - com US\$ 207 milhões (15\%) e US\$ 141 milhões (10\%).

Tabela 2 - Comercialização por tipo de produto no Brasil - 2017

\begin{tabular}{lccc}
\hline Tipo de Produto & Empresas & Produtos & Faturamento (R\$ bilhões) \\
\hline Biológicos & 69 & 265 & 15.409 \\
Específicos* & 91 & 398 & 3.955 \\
Genéricos** & 88 & 2.450 & 9.380 \\
Novos*** & 101 & 1.154 & 26.573 \\
Similares**** & 149 & 2.320 & 14.168 \\
\hline Total & 214 & 6.587 & 69.487 \\
\hline
\end{tabular}

Fonte: Anvisa, 2018.

* Produto obtidos ou elaborados, com finalidade profilática, curativa ou paliativa não passível de ensaio de bioequivalência.

** Contém o mesmo princípio ativo, na mesma dose e forma farmacêutica, é administrado pela mesma via e com a mesma posologia e indicação terapêutica do medicamento de referência, apresentando eficácia e segurança equivalentes à do medicamento de referência. A intercambialidade é assegurada por testes de equivalência terapêutica.

*** Medicamentos novos com princípios ativos sintéticos e semi-sintéticos, associados ou não. 
**** Contém o mesmo ou os mesmos princípios ativos, apresenta mesma concentração, forma farmacêutica, via de administração, posologia e indicação terapêutica, e que é equivalente ao medicamento registrado no órgão federal.

Nota-se também um cenário deficitário para a análise dos insumos utilizados para a fabricação de fármacos. De acordo com Shinzato et al. (2015) aproximadamente 82\% dos ingredientes farmacêuticos ativos empregados na fabricação de $80 \%$ dos medicamentos consumidos no país são obtidos por meio de importações. Estados Unidos e China se apresentam como os maiores exportadores de farmoquímicos (insumos) para a indústria nacional. Esse fenômeno pode ter diversas explicações complementares. Além dos efeitos do câmbio apreciado, da fragmentação produtiva por parte das empresas multinacionais e do estágio competitivo das empresas nacionais ressalta-se que a cadeia produtiva da indústria farmacêutica brasileira é pouco verticalizada (GOMES ET AL, 2014).

A partir dos dados do Anuário Estatístico do Mercado Farmacêutico (2017), elaborado pela Anvisa, é possível constatar que o mercado de medicamentos é composto, em sua grande maioria, por monodrogas, ou seja, medicamentos que têm apenas um princípio ativo em sua composição. Tal categoria corresponde por um faturamento de R $\$ 55.4$ bilhões, 79,7\% do faturamento total. Em adição, a principal via de comercialização destes produtos é através dos distribuidores, seguido pela venda direta à farmácias e drogarias privadas e em terceiro pelas aquisições governamentais, conforme exposto na Tabela 2.

No que tange as empresas do setor, o grupo liderado pela francesa Sanofi e pela Medley e Genzyme apresentaram maior faturamento. Destaca-se a instituição governamental Fundação Osvaldo Cruz em oitava posição.

Tabela 3 - Empresas farmacêuticas que mais faturaram em 2017

\begin{tabular}{clc}
\hline Ranking & \multicolumn{1}{c}{ Grupo/Empresa } & $\begin{array}{c}\text { Faturamento } \\
\text { (R\$ bilhóes) }\end{array}$ \\
\hline 1 & Sanofi/Medley/Genzyme & $>3$ \\
2 & E.M.S./Sigma/Legrand/Nova Química/Germed & $>3$ \\
3 & Sandoz/Novartis/Alcon & $>3$ \\
4 & Roche & $>3$ \\
5 & Aché/Biosintética & $>3$ \\
6 & Hypermarcas/Luper/Neo Química/Brainfarma/Neolatina/Cosmed/Mantercorp & $>3$ \\
7 & Eurofarma/Momenta & Entre 2 e 3 \\
8 & Fundação Osvaldo Cruz & Entre 2 e 3 \\
9 & Pfizer/Wyeth & Entre 2 e 3 \\
10 & Johnson \& Johnson/Janssen-Cilag & Entre 2 e 3 \\
\hline
\end{tabular}

Fonte: Anvisa (2018)

Nota-se que o mercado farmacêutico brasileiro é impulsionado, em grande parte, pela produção de genéricos ${ }^{9}$. Houve uma expansão acelerada das importações de fármacos e insumos. Tal fato resultou em desequilíbrio estrutural da balança comercial, particularmente nos segmentos mais intensivos em conhecimento da indústria farmacêutica (VARGAS et al, 2012).

Apesar do cenário de dinamismo, segundo o Instituto de Estudos para o Desenvolvimento Industrial em 2018, o déficit do segmento de alta intensidade tecnológica aumentou para US\$ 19,4 bilhões. Os produtos farmacêuticos experimentaram déficit recorde de US\$ 7,0 bilhões, com queda de $6,1 \%$ nas exportações.

\footnotetext{
${ }^{9}$ No Brasil, quando a Lei dos Medicamentos Genéricos ( $n^{\circ} 9.787$, de 10 de fevereiro de 1999) entrou em vigor, impulsionou as indústrias nacionais, que passaram a copiar os medicamentos sem patentes. Com o passar dos anos, algumas empresas nacionais de genéricos foram incorporadas por grandes organizações, já que passaram a representar parcela significativa de mercado. Segundo reportagem do Valor Econômico, o volume de medicamentos genéricos e similares no Brasil representou 63\% das vendas totais em 2016 se aproximando do patamar dos países desenvolvidos. Entre as vinte empresas com maior faturamento, oito são nacionais. Disponível em: https:/www.valor.com.br/empresas/5227701/fatia-de-genericos-no-brasil-seaproxima-de-paises-desenvolvidos.
} 
Um dos fatores que podem interferir na evolução da balança comercial, para além do valor tecnológico incorporado, é a variação da taxa de câmbio. Contudo, a FIESP (2013, p. 125) relata que o grau de repasse cambial para o preço das importações farmacêuticas é baixo.

Gráfico 2 - Evolução da Balança Comercial dos Produtos da indústria de transformação de alta intensidade tecnológica - Brasil - US\$ Milhões FOB (2000-2018)

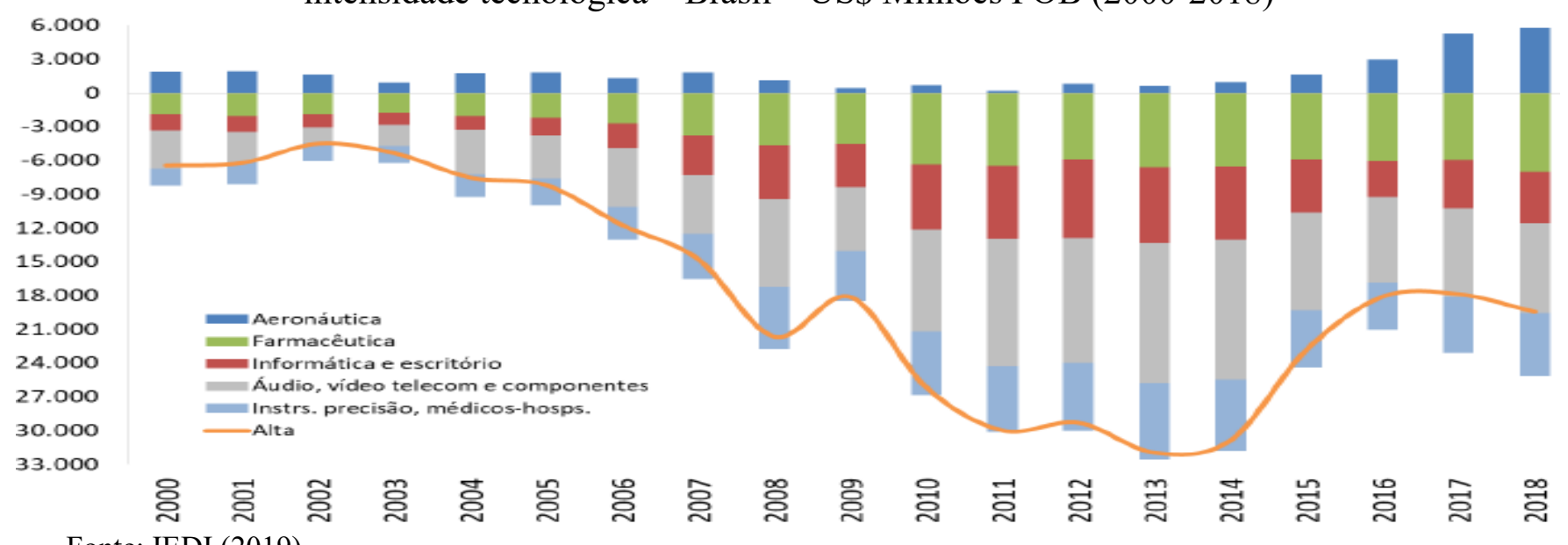

Fonte: IEDI (2019)

O cenário mostra-se que enquanto os produtos farmacêuticos oriundos da biotecnológica estão entre os medicamentos mais vendidos no mundo, cuja participação relativa no mercado farmacêutico global tem crescido expressivamente, aqui no Brasil sua produção ainda é baixa. De acordo com a CNI (2018) em 2016 os produtos de origem biotecnológica responderam por aproximadamente $45 \%$ das vendas entre os 100 principais produtos farmacêuticos no mercado global, ou o equivalente a US\$ 192 bilhões.

Assim, a convergência entre essas diferentes plataformas tecnológicas relacionadas à biologia molecular (genômica, proteômica e outros), bioinformática, nanobiotecnologia, ciências de materiais e outros representa uma tendência global. E deve servir de parâmetro para alterações estruturais da indústria de base química e biotecnológica em saúde no Brasil.

Em termos da infraestrutura científica e tecnológica, a maior parte dos institutos públicos de pesquisa do Brasil conta com grupos consolidados de pesquisa na área da saúde e em algumas áreas de fronteira da biotecnologia, contudo, o descompasso segundo Vargas et al (2012) está "entre o elevado grau de capacitação científica em diferentes áreas da biotecnologia e a limitada capacitação inovativa existente hoje na base produtiva em saúde.".

O descompasso evidencia-se ao se averiguar os estágios da cadeia produtiva da indústria farmacêutica, a saber:

$1^{\mathrm{o}}$ : Pesquisa e desenvolvimento (P\&D);

$2^{\circ}$ : Produção de farmoquímicos;

$3^{\circ}$ : Produção de medicamentos;

$4^{\text {o: }}$ : Marketing e comunicação.

O domínio das empresas multinacionais é explicado pelo fato destas operarem nos quatro estágios. Ressaltando que a etapa destinada a $\mathrm{P} \& \mathrm{D}^{10}$ é executada nos países de origem. Já as empresas nacionais operam, somente, no $3^{\circ}$ e $4^{\circ}$ estágios, impactando em uma baixa taxa de inovação e consequentemente um baixo depósito de patentes (PONTES, 2017).

Segundo Torres-Freire, Golgher e Callil (2014), devido à falta de interesse em inovação das indústrias brasileiras, a maioria dos pesquisadores nacionais trabalha em universidades e institutos de pesquisa e não no setor privado, como ocorre nos países desenvolvidos.

\footnotetext{
${ }^{10}$ As indústrias farmacêuticas brasileiras investiram apenas $1,27 \%$ da sua receita líquida em P\&D, entre os anos de 2003 e 2005. O setor privado brasileiro investe $0,5 \%$ do PIB em P\&D, percentual muito pequeno se comparado a União Europeia (1,15\% do PIB), a média dos países membros da OCDE (1,58\% do PIB) e aos Estados Unidos (2\% do PIB) (TORRESFREIRE; GOLGHER e CALLIL, 2014).
} 
Ou seja, faz-se necessário a constituição de um sistema de inovação eficaz no país, considerando que:

(...) the 'coupling mechanisms' between the education system, scientific institutions, $R \& D$ facilities, production and markets have been an important aspect of the institutional changes introduced in the successful national innovation systems (FREEMAN, 1982).

Uma sinalização que o país está perdendo competitividade, especialmente em biotecnologia, e que a estrutura produtiva do setor não está preparada para uma indústria de ponta é o anúncio de duas multinacionais farmacêuticas. No primeiro semestre de 2019, a americana Eli Lily e a suíça Roche informaram o encerramento de suas atividades no Brasil, como parte da reorganização global de suas operações industriais e de portfólio.

No país, a Eli Lily destaca-se pela produção do remédio Cialis (para disfunção erétil) enquanto a Roche pelo Bactrim (antibiótico), Rivotril, Lexotan e Valium (ansiolíticos), que são itens de baixa complexidade e alta tiragem. Na prática, as companhias vão continuar atuando no Brasil, através de centro de distribuição, mas só com a venda de produtos importados.

A prioridade de ambas é migrar de produtos mais simples, baratos e de grande volume (genéricos) para os inovadores, mais caros, e produzidos em menor escala (medicamentos biológicos e a oncológicos). Grandes farmacêuticas estão investindo em biotecnologia, como é o caso da Eli Lily que comprou a empresa Loxo Oncology por US\$ 8 bilhões no fim de 2018. A Loxo é uma empresa de medicamentos quase personalizados, que atacam os tumores usando informações genéticas e genômicas sobre as mutações e causas do câncer.

A tendência atual é que as farmacêuticas também concentrem suas produções em países que ofereçam melhores condições de incentivos fiscais, infraestrutura e mão de obra qualificada e menor burocratização. Torna-se menos dispendioso produzir os remédios no exterior e depois importá-los para a distribuição no mercado interno.

Segundo dados da Sindusfarma (2018), dos 241 laboratórios registrados junto à Câmara de Regulação do Mercado de Medicamentos, 97 (40\%) possuem o capital de origem internacional e 144 $(60 \%)$ possuem o capital de origem nacional. Atualmente, o setor farmacêutico no Brasil gera cerca de 90 mil empregos diretos, 500 mil indiretos e movimenta mais de R 62,3 bilhões em vendas por ano.

\section{5 - RESULTADOS E DISCUSSÕES}

O sistema de inovação é conceituado como um conjunto de instituições distintas que contribuem para o desenvolvimento da capacidade de inovação e aprendizado de um país, região, setor ou localidade.

Constituem-se de elementos e relações que interagem na produção, difusão e uso do conhecimento. A ideia básica do conceito de sistemas de inovação é que o desempenho inovativo depende não apenas do desempenho de empresas e organizações de ensino e pesquisa, mas também de como elas interagem entre si e com vários outros atores, e como as instituições - inclusive as políticas afetam o desenvolvimento dos sistemas (CASSIOLATO \& LASTRES, 2005).

Segundo Turchi e Morais (2017), embora o Brasil tenha avançado em termos de ações de apoio ao empreendedorismo inovador, as iniciativas, tanto públicas quanto privadas, não foram suficientes para impulsionar o desenvolvimento do ecossistema inovador de forma consistente.

A consecução de estratégias requer: (i) sua priorização no mais alto nível de governo e a existência de metas compartilhadas com contrapartidas com o setor privado; (ii) a realização de investimentos substantivos na capacitação de recursos humanos; (iii) a implementação de regulações e fomento pró-inovação; (iv) a modernização e o aumento da capacidade de resposta do Estado; e (v) a implementação de ações por meio de programas e instrumentos coordenados e alinhados às necessidades das empresas e com monitoramento de resultados (CNI, 2018).

Contudo, o Brasil não dispõe de uma estratégia nacional de inovação de longo prazo. O nosso sistema de ciência e tecnologia enfrenta nos dias atuais uma brutal compressão orçamentária e os 
programas de governo estão focados nas urgências de curto prazo. Tal fato pode ser severamente prejudicial para a superação dos desafios impostos pelas inovações disruptivas.

Diante deste cenário, o setor farmacêutico apresenta elevado grau de vulnerabilidade, uma vez que a dependência tecnológica pode ser elevada mediante o salto tecnológico planejado pelas empresas dos países desenvolvidos.

Verifica-se no país uma dualidade entre a dominância das indústrias transnacionais e uma indústria nacional forte e competitiva, com relevância principalmente após a implementação da lei de Patentes e da lei dos Genéricos (HASENCLEVER, 2004).

A indústria farmacêutica nacional tem estrutura típica de oligopólio diferenciado, no qual existe uma significativa quantidade de empresas, contudo, poucas empresas detém uma parcela relevante do mercado. Estas últimas são subsidiárias das multinacionais que compõem o grupo das grandes farmacêuticas do mundo (big pharmas). Grande parte do faturamento do setor é direcionada a poucas empresas e devido a forte internacionalização (BASTOS, 2005).

Devido ao dinamismo do mercado farmacêutico faz-se necessário estar atento as novas direções e tendências que possa surgir. A empresa de consultoria Boston Consulting Group (BCG) ${ }^{11}$ apresentou sete meios possíveis de desenvolvimento futuro para o segmento farmacêutico:

1. Desenvolvimento de medicamentos biológicos;

2. Desenvolvimento de medicamentos biossimilares;

3. Inovação incremental, por meio do desenvolvimento de melhorias para um produto ou novas aplicações para moléculas que já existem;

4. Inovação radical, por meio do desenvolvimento de novos produtos;

5. Consolidação e união de forças entre as indústrias fabricantes de genéricos;

6. Internacionalização das operações das indústrias brasileiras;

7. Diversificação e ampliação do portfólio.

A indústria farmacêutica nacional requer definir uma estratégia de desenvolvimento que alinhe as demandas internas, pesquisa e desenvolvimento, políticas públicas, capacitação de mão-de-obra, para alcançar a fronteira tecnológica e aumentar a competitividade.

Para Reis et al (2016) o futuro da indústria farmacêutica está condicionado pela evolução das necessidades da demanda por saúde, pela dinâmica setorial da indústria e pelas principais tendências tecnológicas associadas. De um lado, as transições demográficas e epidemiológicas e a carga de incidência das doenças alteram as oportunidades e os desafios do setor; de outro, os avanços inovativos reconfiguram o progresso tecnológico da indústria farmacêutica. Como resultado, se verifica uma tendência de elevação dos custos de saúde, dado a ampliação das necessidades de saúde e a pressão pela inclusão dos novos produtos e tecnologias pelo mercado.

Concomitante a isso, Paranhos e Hasenclever (2013) colocam cinco pontos que servem como uma forma sólida de ganhar competitividade e produtividade do setor farmacêutico frente aos concorrentes internacionais. Esses pontos visam melhorar a relação entre empresas do segmento e universidades, de forma que alinhem os objetivos do mercado e as pesquisas científicas.

1) necessidade de fortalecer a estrutura interna de $P \& D$ nas empresas farmacêuticas para a geração de inovação e para melhorar a interação com o setor acadêmico;

2) necessidade de reestruturar e modernizar a estrutura interna das universidades;

3) necessidade de um planejamento prévio das ações do governo e da criação de um ambiente propício para a inovação;

4) papel fundamental desempenhado pelo financiamento do governo e apoio às atividades inovadoras das empresas e para os NITs das universidades, ainda que apenas em sua fase inicial;

5) necessidade de regulação e regulamentação eficiente do setor farmacêutico.

Empresas e universidades são elos importantes com alto potencial para interagir e desenvolver inovações. Ambos estimulados pelas ações governamentais, por meio de políticas industrial e tecnológica coerente, podem configurar como uma estratégia de desenvolvimento de longo prazo eficaz para que o Brasil consiga destaque frente aos mercados internacionais.

${ }^{11}$ Disponível em: <https://blog.ipog.edu.br/saude/industria-farmaceutica-ascensao/>. 
Reis et al (2016) aponta dois possíveis cenários para o setor farmacêutico brasileiro. No cenário mais pessimista, a possível descontinuidade de políticas públicas e a falta de estratégias de longo prazo, resultariam na especialização das empresas brasileiras na produção e comercialização de produtos com pouca diferenciação, basicamente medicamentos genéricos e com reduzida capacidade de realizar investimentos em P\&D. A inovação continuaria atrelada apenas aos países mais desenvolvidos tecnologicamente e poderia ocorrer um enfraquecimento da saúde pública no Brasil. Como resultado haveria um aprofundamento do déficit de conhecimento da indústria e diferenças de acesso à saúde entre indivíduos ricos e pobres.

Em um cenário otimista, espera-se que o investimento do setor farmacêutico seja direcionado para a inovação incremental, por meio do aprimoramento de medicamentos já existentes. Adquirir competências em inovação incremental é relevante na busca de novas moléculas sintéticas e biológicas (isto é, inovação radical) e pode contribuir no aumento da competitividade internacional e tornar o setor intensivo em conhecimento. Assim, incorporar novas tecnologias para racionalizar o sistema leva a ampliação do acesso da população a produtos para saúde (REIS et al, 2016).

\section{6 - CONSIDERAÇÕES FINAIS}

Um dos maiores desafios impostos ao setor privado consiste na superação do atraso tecnológico brasileiro na produção de medicamentos de origem biotecnológica. Por mais que a indústria farmacêutica nacional tivesse evoluído desde o início dos anos 2000, a produção de biofármacos e de bioquímicos representa um novo paradigma tecnológico a partir da Quarta Revolução Industrial.

De forma resumida e não exaustiva, os principais desafios institucionais e sistêmicos parecem estar relacionados: (1) à oferta adequada de capacidade científica em saúde; (2) à indução de pequenas empresas com foco nas tecnologias com potencial de disrupção - startups; (3) ao enfrentamento da questão dos prazos no processo de concessão e análise de patentes; e (4) ao aperfeiçoamento de mecanismos de utilização do poder de compra público para induzir a inovação em saúde.

Considerando que a indústria 4.0 não depende de inovações radicais, mas de uma convergência de tecnologias, as ações empresariais e políticas públicas também deverão estar alinhadas. Faz-se necessário um redesenho institucional, uma vez que a existência desse quadro traz importantes implicações, seja em termos da vulnerabilidade econômica e tecnológica para o sistema nacional de saúde, seja pelo risco de que a base produtiva em saúde no Brasil se acomode a um padrão pouco inovador.

No Brasil, é constatada a ausência de uma estratégia de inovação de longo prazo para a indústria farmacêutica, que possa ultrapassar os limites impostos pelas inovações disruptivas. Alguns fatores são apontados como destaques para planejamento e definição de metas pautadas no desenvolvimento das empresas e no crescimento econômico do segmento.

O ramo farmacêutico é intensivo em ciência e conhecimento; gera e difunde conhecimento científico; contribui para a formação de recursos humanos altamente qualificados; gera produtos com agregação de valor; contribui para o crescimento econômico, gera divisas e melhora os termos de troca dos países; além de ter um forte impacto social.

Aliar essas características do setor a uma agenda política-institucional coordenada e eficaz próinovação se traduz em uma estratégia eficiente para ganhar competividade internacional e aumentar a produtividade nacional.

No país, o que se observa são estratégias desarticuladas e de curtíssimo prazo, juntamente a um ambiente macroeconômico incerto, marcado pelo baixo crescimento econômico, elevado nível de desemprego, e corte nos recursos financeiros destinados a ciência e tecnologia. Enquanto nos países analisados (Estados Unidos, Alemanha e China) as estratégias do segmento estão articuladas a partir de políticas públicas específicas e bem concatenadas.

Após três revoluções industriais, e sabendo que se está na quinta onda de inovação da indústria farmacêutica, onde há a prevalência de tecnologias digitais e biotecnologia, o Brasil parece estar atrasado no processo de desenvolvimento, ficando para trás na corrida de incrementos tecnológicos farmacêuticos. Cabe ao país buscar soluções para reverter esse cenário, ou pelo menos reduzir a vulnerabilidade do segmento no Brasil. 
Este artigo pretendeu fazer um panorama do setor farmacêutico do Brasil comparando com os países que apresentaram maior destaque na comercialização e produção destes bens. Contudo, o debate não foi exaurido e cabe mais aprofundamento da análise.

\section{REFERÊNCIAS}

ALCANTARA, T.; NEVES, C. Indústria 4.0: como a tecnologia fez surgir a Quarta Revolução Industrial. Revista Inovação/Unicamp, ago, 2016.

ACHILLADELIS, B. The dynamics of technological innovation: The sector of antibacterial medicines. Research Policy, n. 22, p. 279-308, 1993.

ACHILLADELIS, B. Innovation in the Pharmaceutical Industry. In: LANDAU R. et al. Pharmaceutical Innovation: Revolutionizing Human Health. Philadelphia, PA: Chemical Heritage Press, 1-147, 1999.

ACHILLADELIS, B.; ANTONAKIS, N. The Dynamics of Technological Innovation: the case of the pharmaceutical industry. Research Policy, 30, p. 535-588, 2001.

ANVISA. Anuário Estatístico do Mercado Farmacêutico 2017. Brasília, 2018.

ARBIX, G.; MIRANDA, Z.; TOLEDO, D.; \& ZANCUL, E. Made in China 2025 e Industrie 4.0: a difícil transição chinesa do catching up à economia puxada pela inovação. Tempo Social, v. 30 n. 3, p. 143-170, 2018.

Associação da indústria farmacêutica de pesquisa - INTERFARMA. Guia Interfarma 2017. São Paulo, 2018.

BASTOS, V.D. Inovação Farmacêutica: padrão setorial e perspectivas para o caso brasileiro. BNDES Setorial, Rio de Janeiro, n. 22, p. 271-296, set. 2005.

CASSIOLATO, J.E.; LASTRES, H. M. M. Sistemas de inovação e desenvolvimento as implicações de políticas. São Paulo em Perspectiva, v. 19, n. 1, p. 34-45, jan./mar. 2005.

CHERIF, R.; HASANOV, F. The return of the policy that shall not be named: principles of industrial policy. IMF Working Paper, 2019.

CIMOLI, M.; DOSI, G.; NELSON, R.; STIGLITZ, J. Instituições e políticas moldando o desenvolvimento industrial: uma nota introdutória. Revista Brasileira de Inovação, v. 6, n. 1, p. 55-85, jan./jun. 2007.

CONFEDERAÇÃO NACIONAL DA INDÚSTRIA - CNI. Mapa estratégico da indústria 2018 - 2022. Brasília, 2018.

COHEN, W., M.; LEVINTHAL, D. A. Absorptive Capacity: A New Perspective on Learning and Innovation, ASQ, v. 35, p. 128-152, 1990.

FIESP. Estudos sobre a Taxa de Câmbio no Brasil, 2013. Disponível em: www.fiesp.com.br/arquivodownload/?id=139236. Acesso em: 08 fev. 2019.

FREEMAN, C. Technological infrastructure and international competitiveness. Paris: OECD, aug. 1982. 
GALINDO-RUEDA, F.; VERGER, F. Verger. OECD Taxonomy of Economic Activities Based on R\&D Intensity. Paris. OECD Science, Technology and Industry, 2016. Working Papers.

GOMES, R. et al. O novo cenário de concorrência na indústria farmacêutica brasileira. BNDES Setorial, Rio de Janeiro, n. 39, p. 97-134, abr. 2014.

HASENCLEVER, L. et al. O Mercado de Medicamentos Genéricos no brasil. In: Simpósio francobrasileiro o novo direito da propriedade intelectual no domínio da saúde e dos seres vivos. Brasília, 2004. Anais. Brasília: TPI, 2004.

HATZICHRONOGLOU, T. Revision of the high-technology sector and product classification. Paris: OECD Science, Technology and Industry, 1997. Working paper n. 1997/02).

Instituto de Estudos para o Desenvolvimento Industrial - IEDI. Indústria e o Brasil do futuro. Disponível em: https://iedi.org.br/media/site/artigos/20180918_industria_e_o_brasil_do_futuro.pdf. Acesso em: 08 dez. 2018.

A caminho do passado: A balança comercial da indústria em 2018. Edição 905. Disponível em: iedi.org.br/cartas/carta_iedi_n_905.html. Acesso em: 09 dez. 2018.

KORNIS, G. E. M.; BRAGA, M. H.; DE PAULA, P. A. B. Transformações recentes na indústria farmacêutica: um exame da experiência mundial e brasileira no século XXI. Physis Revista de Saúde Coletiva, Rio de Janeiro, v. 24, n. 3, p. 885-908, 2014.

LABRUNIE, M. L. Políticas industriais na era da manufatura avançada: uma comparação internacional. 2018. Dissertação retirada em Economia - UFRJ, Rio de Janeiro, 2018.

LANDAU, R. et al, Pharmaceutical innovation: Revolutionizing Human Health. San Francisco: Chemical Heritage Press, 1999.

LAZONICK, W.; O'SULLIVAN, M. Maximizin shareholder value: a new ideology for corporate governance. Economy and Society, v. 29, n. 1, 2000.

LOBO, L.C. Inteligência artificial e medicina artificial. Revista Brasileira de Educação Médica, v. 41, n.2, p.185-193, 2017.

O'SULLIVAN, E. et al. What is new in the new industrial policy? A manufacturing systems perspective. Oxford Review of Economic Policy, v. 9, n 2, p. 432-462, 2013.

PARANHOS, J.; HASENCLEVER, L. O sistema farmacêutico de inovação e o relacionamento empresauniversidade no setor farmacêutico do Estado do Rio de Janeiro. Cadernos do Desenvolvimento Fluminense, Rio de Janeiro, n. 2, jul. 2013.

PAVITT, Keith. Sectoral patterns of technical change: towards a taxonomy and a theory. Research Policy, v. 13, n. 6, p. 343-373, 1984.

PONTES, C.E.C. Patentes de medicamentos e a indústria farmacêutica nacional: estudos dos depósitos feitos no Brasil. Revista Produção e Desenvolvimento, v.3, n.2, p.38-51, ago, 2017.

RADAELLI, V. Trajetórias inovativas do setor farmacêutico no Brasil: tendências recentes e desafios futuros. 2012. Tese de doutorado em Geociência - Unicamp, Campinas, 2012. 
REIS, Carla; PIMENTEL, Vitor; PIERONI, João Paulo; MITIDIERI, Thiago. Indústria Farmacêutica. Panoramas Setoriais 2030. 2016.

SANTOS, M. E. Política de incentivo â inovação no âmbito do Complexo Econômico Industrial da Saúde: avaliação do mecanismo CT-Saúde e Profarma - BNDES no período de 2002 - 2012. 2014. Tese de doutorado em Saúde Pública - Fiocruz, Rio de Janeiro, 2014.

SARTI, F.; HIRATUKA, C. Indústria mundial: mudanças e tendências recentes. Campinas: UNICAMP, dez. 2010. Texto para discussão, n. 186.

SCHWAB, Klaus. The Fourth Industrial Revolution: what it means, how to respond. Disponível em: https://www.weforum.org/agenda/2016/01/the-fourth-industrial-revolution-what-it-means-and-how-torespond/. 2016. Acesso em: fev. 2019.

SCHWAB, K.; DAVIS, N. Aplicando a quarta revolução industrial. São Paulo: Edipro, 2018.

SHINZATO, K. Y.; POLLI, M.; PORTO, G. S.. Tendências recentes do setor farmacêutico no Brasil: desempenho financeiro e operacional, fluxos de comércio exterior e atividades desempenhadas em inovação tecnológica. $R A C E F$ - Revista de Administração, Contabilidade e Economia da Fundace, v. 6, n. 1, p. 29-128, 2015.

SINDUSFARMA. Perfil da indústria farmacêutica 2018 e aspectos relevantes do setor. Disponível em: http://sindusfarma.org.br/arquivos/Perfil-IF2018.pdf. Acesso em: jan. 2019.

TEIXEIRA, A. A indústria farmacêutica no Brasil: um estudo do impacto socioeconômico dos medicamentos genéricos. Monografia apresentada a FCL/Unesp. Araraquara, 2014.

TESSERIN, M., S.; SUZIGAN, W. GUILHOTO, J.J.M. Inovação no Brasil por intensidade tecnológica: cooperação e origem do capital. São Paulo: USP, 2019. (Working Paper).

TESSARINI, G. ; SALTORATO P. Impactos da indústria 4.0 na organização do trabalho: uma revisão sistemática da literatura. Revista Produção Online, Florianópolis, SC, v. 18, n. 2, p. 743-769, 2018.

TORRES-FREIRE, C.; GOLGHER, D.; CALLIL, V. Biotecnologia em saúde humana no Brasil: produção científica e pesquisa e desenvolvimento. Novos Estudos - CEBRAP, n. 98, p. 69-93, 2014.

TURCHI, L. M. MORAIS, J. M. Políticas de Apoio à Inovação Tecnológica no Brasil: avanços recentes, limitações e propostas de ações. Brasília: Ipea, 2017.

URIAS, E. M P. A indústria farmacêutica brasileira: um processo de co-evolução de instituições, organizações industriais, ciência e tecnologia,2009. Dissertação de Mestrado em Política Científica e Tecnológica - Unicamp, Campinas, 2009.

VARGAS, M; GADELHA, C. A. G.; COSTA, L.; MALDONADO, J. Inovação na indústria química e biotecnológica em saúde: em busca de uma agenda virtuosa, 2012.

VARGAS, M. A.; GADELHA, C. A G..; MALDONATO, J. M.; BARBOSA, P.R. Reestruturação na indústria farmacêutica mundial e seus impactos na dinâmica produtiva e inovativas do setor farmacêutico brasileiro. In: XV Encontro Nacional de Economia Política, São Luís, 2010. 